\title{
Google Sky y los estándares de catalogación: un ejemplo de divergencia entre la información astronómica existente y la que se puede describir
}

\author{
M. Pilar Alonso-Lifante*, Celia Chaín-Navarro* \\ * Universidad de Murcia, España \\ Correo-e: mp.alonsolifante@um.es, chain@um.es
}

Recibido: 03-07-2012; 2a versión: 16-11-2012; aceptado: 08-01-2013.

Cómo citar este artículo/Citation: Alonso-Lifante, M. P.; Chaín-Navarro, C. (2013). Google Sky y los estándares de catalogación: un ejemplo de divergencia entre la información astronómica existente y la que se puede describir. Revista Española de Documentación Científica, 36(4):e020. doi: http://dx.doi.org/10.3989/redc.2013.4.1000

\begin{abstract}
Resumen: Se realiza una revisión tanto de la información astronómica que ofrece Google Sky como la que permiten describir MARC21, ISBD consolidada y RDA, para demostrar que no se han contemplado hasta el momento determinados parámetros astronómicos y astrofísicos, susceptibles de convertirse en futuros campos de descripción de estos estándares. Dichos campos permitirán realizar descripciones mucho más completas y adecuadas de diferentes recursos astronómicos como material cartográfico. En concreto, se analizan exclusivamente aquellos objetos celestes contenidos en imágenes astrofotográficas que pueden encontrarse en archivos y bibliotecas astronómicas. Para ello, primero se realiza una síntesis de la información astronómica que ofrecen Google Sky y las bases de datos a las que enlaza, SIMBAD y NED. Posteriormente se indican los campos de descripción de los que disponen estos estándares para describir material cartográfico celeste y, por último, se realiza una propuesta de los parámetros mínimos deseables relevantes que podrían incluirse en un registro.
\end{abstract}

Palabras clave: Google Sky; SIMBAD; NED; catalogación; MARC 21; ISBD consolidada; RDA; descripción de cartografía celeste; imágenes astronómicas; recuperación de información astronómica.

Google Sky and cataloguing standards: an example of the divergence between the most queried astronomical information and what cataloguing standards allow us to describe

\begin{abstract}
A survey has been carried out on the astronomical information supplied by Google Sky and the information which can be described using the standards MARC21, ISBD consolidated edition, and RDA. The main goal of the study is to show that some astronomical and astrophysical information is still not taken into account in describing different astronomical resources as well as cartographic material. This information could eventually be incorporated as description fields of the aforementioned cataloguing rules. Such fields would allow us to carry out a much more complete and adequate description of these astronomical resources. We have focused on celestial objects appearing in astronomical images which can be found in astronomical archives and libraries. First a brief survey of astronomical information supplied by Google Sky and its linked databases, SIMBAD and NED is performed. Subsequently, we show how the existing description fields describe celestial cartographic materials, and finally we present a new proposal consisting of the desirable minimum parameters which could be included in bibliographic records.
\end{abstract}

Keywords: Google Sky; SIMBAD; NED; cataloguing; MARC 21; ISBD consolidated edition; RDA; celestial cartographic material description; astronomical images; astronomical information retrieval.

Copyright: () 2013 CSIC. Este es un artículo de acceso abierto distribuido bajo los términos de la licencia Creative Commons Attribution-Non Commercial (by-nc) Spain 3.0. 


\section{INTRODUCCIÓN}

\subsection{Evolución histórica de los recursos astronómicos}

La fascinación por el cielo nocturno y los fenómenos celestes ha llevado al ser humano a registrar eventos de este tipo desde tiempos ancestrales. Con el tiempo, el registro de la información de tipo astronómico ha acabado convirtiéndose en una práctica esencial de incalculable valor (Accomazzi, 2010). En este sentido, uno de los ejemplos más destacables de la importancia de registrar este tipo de información lo constituye la publicación de las famosas leyes de Kepler, cuyo descubrimiento fue posible gracias al catálogo de observaciones efectuadas por su antecesor y maestro Tycho Brahe (Lachièze-Rey y Luminet, 2001).

A lo largo de la historia han ido apareciendo distintos documentos que reflejaban de una forma u otra el estado del cielo nocturno. Los más conocidos reciben el nombre de "cartas celestes", a menudo agrupadas en "atlas celestes" (Kanas, 2009). Una carta celeste no es más que una representación plana de una región del cielo nocturno (o de éste en su totalidad) mostrando todos los objetos visibles hasta un determinado brillo. Junto a éstas, los "catálogos celestes" ofrecían información específica conocida sobre los objetos que aparecían en las cartas. Entre esta información destaca la posición de los astros en un determinado sistema de coordenadas y la "magnitud de brillo" de los objetos observados. Las cartas celestes se erigieron en el documento astronómico por excelencia durante siglos, sin embargo, la revolución que supuso la nueva teoría planetaria de Copérnico y la aparición de nuevos y más precisos instrumentos de observación como el telescopio, produjeron un vuelco en la importancia de ambos tipos de documentos. En efecto, a partir de aquel momento, el valor científico de los datos tomados durante las observaciones comenzaba a ser superior al valor artístico de la representación pictórica de la carta. Tanto es así que, por un lado, las cartas celestes eran a menudo enviadas como regalos a los reyes de la época por parte de los astrónomos y, por otro, sirva de ejemplo que el prestigioso científico Isaac Newton suspiraba por conocer los datos que el astrónomo real John Flamsteed había anotado en su catálogo sobre la trayectoria de la Luna, y poder así constatar sus teorías (Durán, 2012).

Generalmente, los catálogos celestes presentan una serie de tablas con datos numéricos en las que las filas contienen los nombres de los objetos y las columnas reflejan los tipos de datos que se ofrecen de dichos objetos. Por ejemplo, en un catálogo de estrellas pueden encontrarse tablas en las que sus filas contienen los nombres de las distintas estrellas y sus columnas ofrecen diversos datos de interés sobre éstas (posición, distancia, brillo, etc.). Como puede advertirse, estas columnas representan los tipos de datos por los que el autor del catálogo decide catalogar ese objeto. En otras palabras, puede decirse que las columnas de los catálogos celestes representan los "metadatos" asociados a ese tipo de objeto por parte del autor del catálogo. En definitiva, en el mundo de la Astronomía son los propios investigadores (astrónomos y astrofísicos) los que catalogan los objetos celestes que van descubriendo.

La aparición de la Astrofotografía, unida a la construcción de telescopios cada vez más sofisticados durante los siglos XIX y XX propiciaron la aparición de un nuevo tipo de documento astronómico: las imágenes astrofotográficas. Éstas, a diferencia de las cartas y mapas celestes, suelen contener la imagen de un único objeto celeste (una estrella, galaxia, cúmulo estelar, etc.) o de un número reducido de ellos. Además, la aparición en los años 50 del radiotelescopio supuso una gran revolución en el mundo de la cartografía celeste ya que, por primera vez, podíamos ver imágenes de objetos celestes muy distantes, en otras longitudes de onda fuera del espectro visible.

Por su parte, el inicio de la carrera espacial a finales de los 50 y la aparición de los ordenadores marcaron un antes y un después en el volumen de información astronómica que era necesario registrar para su posterior análisis. En efecto, misiones espaciales y proyectos de investigación asociados al estudio del cosmos con potentes telescopios generan hoy día cantidades ingentes de datos que son recopilados y almacenados en enormes bases de datos accesibles desde cualquier ordenador conectado a Internet.

Sin embargo, cada vez son más los estudios que se realizan con objeto de medir la precisión de los datos existentes en antiguas cartas celestes, imágenes astrofotográficas y catálogos celestes (Verbunt y Van Gent, 2010a, 2010b, 2012; Rivera, 2012; Bhattacharjee, 2009; McNally, 2001). El objetivo de tal campaña no es otro que el de disponer de datos fiables varios siglos atrás que permitan estudiar, con mucha diferencia de tiempo, fenómenos astronómicos de extraordinaria lentitud, con objeto de corroborar las teorías científicas que han visto luz durante toda la historia de la Ciencia.

\subsection{La documentación astronómica en un mundo globalizado y altamente especializado}

Tal como se desprende del apartado anterior, el desarrollo de la Ciencia de la Documentación ha estado, y estará, intrínsecamente ligado a la evolución de la tecnología. A medida que los nuevos instrumentos de observación han ido arrojando nuevos datos astronómicos de relevancia, los profesionales del sector se han visto en la necesidad de registrar dichos datos con objeto de catalogar y clasificar los objetos celestes observados, y con ellos la totalidad del universo conocido. En consecuencia, cada nuevo avance tecnológico y científico supone subir nuevos peldaños en el nivel de especialización, no solo del conocimiento generado, 
sino también de la documentación que sustenta y preserva dicho conocimiento.

En este sentido, la Astronomía y la Astrofísica son dos ciencias que han alcanzado elevados niveles de especialización, favorecidas en buena parte por el continuo proceso de globalización en el que nos encontramos inmersos. Es por esto por lo que los documentos que estas ciencias generan son muy especializados, así como también lo son las búsquedas que realizan los profesionales de estos sectores en bases de datos especializadas. Sin embargo, ¿por qué no realizamos entonces descripciones especializadas de los recursos astronómicos de los que disponemos en nuestros archivos y bibliotecas? La respuesta a esta pregunta supone volver a la esencia misma de la catalogación, recordar que describimos nuestros recursos astronómicos para que sus usuarios puedan recuperarlos, siendo dicha recuperación el objetivo final de la descripción documental. En palabras de Ricky Erway (refiriéndose a las colecciones especiales) "necesitamos encontrar mejores formas de describir nuestras colecciones para que los usuarios puedan encontrarlas" (Erway, 2012).

Como es natural, en este proceso de búsqueda de mejores descripciones documentales, los bibliotecarios y demás profesionales de la información debemos jugar un papel protagonista. A este respecto, A. Heck afirma que "está claro que hemos entrado en una nueva era donde los bibliotecarios han adoptado una nueva postura en cuanto a la recuperación de información al mismo tiempo que los científicos presentan también una actitud renovada hacia los bibliotecarios" (Heck, 1993). Sin embargo, para ejercer este papel protagonista debemos adoptar una postura muy activa y dinámica, es decir, debemos familiarizarnos con la información astronómica y su tipología, aprender a manejarla y conocer muy bien todas las fuentes y canales de información. Todo ello con el objetivo de erigirnos en verdaderos y necesarios intermediarios entre los investigadores y la documentación que estos manejan a diario, así como establecer aquellos datos necesarios para una mejor descripción que permita una recuperación de información satisfactoria (Kumar, 2010; Lagerstrom y Grothkopf, 2010; Grothkopf, 2011).

\subsection{Los estándares de catalogación y la problemática de las bibliotecas astronómicas}

En estos momentos en los que estamos asistiendo a cambios en los estándares de catalogación (Sainz, 2012), se está incidiendo notablemente en la creación de normativas adaptadas a la tecnología de la web semántica. Sin embargo, no se está apostando tanto por realizar una verdadera descripción con cierta profundidad de los contenidos de los recursos, es decir, una descripción que permita indicar los datos mínimos deseables de cada tipo de recurso.
A este respecto, nuestra aportación se centra en el nivel de representación de datos en el que se encuentran las reglas de catalogación dentro de la propuesta de clasificación de los estándares para el control bibliográfico que proponen Picco y Ortiz (2012). Se trata de una aportación centrada en la mejora de la descripción del contenido de las imágenes celestes procedentes de proyectos y misiones espaciales. Según las autoras, como sabemos, MARC21 es un estándar de almacenamiento ("aplicación informática que recoge de forma sistemática las descripciones y representaciones del universo bibliográfico"), mientras que ISBD consolidada y RDA son estándares de descripción ("instrucciones o reglas específicas que nos permiten representar de una manera simbólica el universo bibliográfico"). A pesar de esta distinción, en la práctica, aunque la Library of Congress recientemente (a fecha de noviembre de 2012) ha anunciado que BIBFRAME sustituirá al formato MARC21 (Library of Congress, 2012a; Picco y Ortiz, 2012; Estivill-Rius, 2011), se observa que este estándar es el que más elementos permite describir de un recurso astronómico (sección 4), frente a otras normas tales como ISBD consolidada y RDA (veremos que la diferencia no es muy significativa, pero existe). A pesar de todo, hoy en día MARC 21 es un estándar que sigue actualizándose constantemente y en torno al mismo se ha realizado un gran esfuerzo para hacerlo compatible con la web semántica. En efecto, $M A R$ $C X M L, M A R C$ in FRBR, RDA in MARC, MARC Code Lists as Linked Data, son algunas de las iniciativas que ha llevado a cabo la Library of Congress estos últimos años (Library of Congress, 2012b).

Por su parte, ISBD también ha experimentado actualizaciones recientemente. La última ha sido la publicación de ISBD consolidada en junio de 2011 (ISBD, 2011) donde los datos referidos al material cartográfico en esta nueva edición se presentan en el área 3.1. También la IFLA, como responsable de la publicación de este estándar y con el fin de adaptar ISBD a la web semántica, ha creado el grupo de trabajo ISBD/XML Study Group que está trabajando con la tecnología Linked Data (Interoperability of ISBD within Linked Data Environment) y, recientemente, en septiembre de 2012, ha publicado la asignación de nombres de la edición consolidada en lenguaje RDF (Resource Description Framework) (IFLA, 2012).

Con respecto al nuevo código de catalogación que sustituye a las AACR2, RDA (Resource, Description \& Access) fue publicado en julio de 2010 después de aproximadamente 10 años de trabajo, y está basado tanto en el modelo FRBR (publicado en 1998) y en el FRAD (publicado en marzo de 2009) como en los Principios Internacionales de Catalogación (publicados en 2009) que sustituyen a los de París de 1961. A pesar de su mejor adaptación tecnológica, sustentada en un diseño enfocado a los entornos electrónicos, al principio no tuvo una buena aceptación por parte de la comunidad bibliotecaria, por lo que se decidió realizar un test 
en EEUU para determinar la conveniencia de su implantación. Uno de los resultados del test indicó que "los errores aumentan con la dificultad del material catalogado y no dependen tanto del código empleado" (Estivill-Rius, 2011). Este es uno de los motivos por los que son pocos los autores que han tratado cómo afectan al material cartográfico las RDA, en particular, y los estándares de catalogación, en general. Entre ellos podemos destacar a Paige G. Andrew y Mary Larsgaard, autores que tienen previsto publicar en 2013 un libro titulado "RDA and Cartographic Resources", editado por la American Library Association (ALA). Otro material interesante de Andrew sobre los cambios que introduce RDA respecto a otros estándares como AACR2 y MARC 21 , es una charla que dio en el año 2011 organizada por la ALCTS (The Association for Library Collections and Technical Services) (Andrew, 2011).

Para Andrew la aportación más importante que hace RDA es centrarse en las relaciones, es decir, basarse en el modelo OEMI (Obra, Expresión, Manifestación, Ítem) e incidir en la necesidad de incluir, si es posible, coordenadas en los registros de mapas y otros materiales cartográficos. Según este mismo autor, el poder del modelo OEMI será apreciado cuando nos desprendamos definitivamente del formato MARC y lo sustituyamos por un nuevo estándar basado en datos (idea compartida por Escolano, 2011). Sin embargo, Mary Larsgaard comenta que, aunque el importante cambio conceptual que incorpora RDA parece ser también el modelo OEMI, RDA no permite realizar una descripción profunda de los diferentes recursos cartográficos. En su opinión, lo que hace RDA es tomar la mayoría de las reglas de las AACR2, reorganizarlas, y con frecuencia renombrarlas.

En efecto, por un lado, a pesar de que RDA se centra en la descripción y acceso a los recursos, no permite una descripción profunda de los mismos (incluidos los astronómicos), aunque por otro lado sí que potencia el acceso, permitiendo la creación de relaciones y asociaciones más ricas entre los diferentes registros, al emplear el modelo entidadrelación que presenta FRBR (Picco-Gómez, 2007). Sobre la aplicación de FRBR al material cartográfico se han escrito algunos trabajos interesantes, entre los que merece la pena destacar McEathron, 2002; Larsgaard, 2007; Kalf, 2008 y Morse, 2012.

En conexión con el estudio norteamericano citado anteriormente, las imágenes celestes son un tipo de material presente en bibliotecas astronómicas cuya catalogación no es tarea sencilla. Esta dificultad, unida a las escasas posibilidades de incluir en los registros la rica información astronómica disponible $y$, en numerosas ocasiones, a la falta de recursos técnicos y humanos, hace que las bibliotecas astronómicas tengan que catalogar sus fondos sin poder acudir a los estándares tradicionales de catalogación disponibles. Por citar un par de ejemplos de especial relevancia a nivel europeo, la biblioteca de la Royal Astronomical Society (RAS) (RAS, 2012) tiene disponibles imágenes astronómicas que sirven vía Internet a través del portal Science Photo Library (SPL). Dichas imágenes son catalogadas mediante un título, fecha, código de identificación, un pie de foto con información sobre la imagen y un conjunto de palabras clave (Science Photo Library, 2012). Por su parte, la biblioteca del Instituto de Astronomía de la Universidad de Cambridge tiene un repositorio digital de imágenes llamado "DSpace digital repository", en el cual, si se busca el nombre de un objeto existente en el repositorio, el sistema devuelve una tabla en la que cada fila es una imagen del objeto buscado, y cada columna representa un tipo de dato por el que se decidió catalogar cada imagen. Las monografías están catalogadas empleando MARC21, y es el propio personal de la biblioteca el que escanea las imágenes y las cataloga para incluirlas en el citado repositorio. En definitiva, puede apreciarse que, ante la falta de opciones para realizar una buena descripción con los estándares disponibles, estas importantes bibliotecas optan por crear repositorios cuyas interfaces están basadas en la incorporación de los "metadatos" disponibles (Schaffner, 2009).

\subsection{La aportación de Google Sky y las bases de datos especializadas}

Durante estos últimos años la sociedad ha sido testigo de una importante revolución en el mundo de la geoinformación. En muy poco tiempo se ha pasado de disponer de sencillos callejeros con los que guiarse, a la puesta en funcionamiento de los sistemas de posicionamiento global (GPS - Global Positioning System), así como a la aparición de software gratuito que permite navegar virtualmente por casi cualquier lugar del mundo a través de cualquier ordenador con conexión a Internet. Programas como Google Earth han supuesto una verdadera revolución en el mundo de la navegación, que actualmente continúa traspasando todo tipo de fronteras. De hecho, dicho programa ofrece la posibilidad no sólo de navegar por tierra (Earth) (2012a) sino también por el cielo nocturno (Sky) (2012b), entre otras aplicaciones.

Dentro del software libre disponible (Mc Cool, 2009), hemos decidido apoyar nuestra investigación en Google Sky, en primer lugar por ser el más mediático, al tratarse de la aplicación astronómica de la empresa Google (tercera marca más valiosa del mundo según el estudio BrandZTM Top 100 Most Valuable Global Brands 2012); y en segundo lugar, porque enlaza con dos grandes e importantes bases de datos astronómicas a nivel mundial: SIMBAD (Set of Identifications Measurements and Bibliography for Astronomical Data) (SIMBAD, 2012a) y NED (NASA/IPAC Extragalactic Database) (NED, 2012a).

Como veremos en la sección 3, SIMBAD es una base de datos gestionada por el Centro de Datos 
Astronómicos de Estrasburgo (CDS) a la que llegan imágenes en formato FITS (Flexible Image Transport System) (modo de almacenamiento que contiene una cierta cantidad de metadatos) y datos procedentes de proyectos de investigación y misiones espaciales (ProEspacio, 2011). Una vez analizados los datos, se procede a un proceso de selección de metadatos que añadir a la imagen. Algunos de esos metadatos proceden del propio registro FITS, una vez descartados los datos erróneos que este formato pudiera contener. Además, hay que tener en cuenta el hecho de que puede existir información de proyectos diferentes que observan las mismas regiones del cielo, por lo que el proceso de selección de metadatos relevantes debe ser especialmente cuidadoso. De la misma forma, NED se sirve y colabora con distintos proyectos de investigación en materia de Astronomía. Al igual que en SIMBAD, cuando llegan las imágenes a la base de datos, antes de almacenarlas se preparan sus metadatos que proceden del formato de entrada FITS así como de datos publicados en artículos y sitios web especializados.

En definitiva, el descomunal volumen de información que los observatorios y proyectos de investigación generan (del orden de TeraBytes mensuales (Hernández y otros, 2009)), no solo justifican la existencia de estas grandes bases de datos, sino que evocan, de forma implícita, la necesidad de gestionar esta información aplicando todas las técnicas a nuestro alcance, de manera que permitan dotar dicha información de un valor añadido. Y es aquí donde los profesionales de la documentación juegan un papel importante. Por citar un ejemplo, el personal que trabaja en estas bases de datos ya se encuentra inmerso en estudios de aplicación de técnicas de data mining así como web mining (Wenger y Oberto, 2010), debido a la creciente interoperabilidad entre NED y distintos archivos astronómicos y otros servicios. Estas técnicas (Mazzarela, 2001) forman parte de las nuevas aplicaciones para Observatorios Virtuales que se están aplicando en NED. Todo ello constituye el presente, pero sobre todo el futuro, de estas mega-bases de datos en las que los documentalistas no debemos tener un papel menor.

\section{OBJETIVO Y ASPECTOS METODOLÓGICOS}

Se pretende demostrar que existen parámetros de gran interés en Astronomía y Astrofísica que no aparecen recogidos en la normativa de catalogación y que son susceptibles de convertirse en futuros campos de descripción de los recursos astronómicos. Para ello nos basamos en el análisis de Google Sky y las dos bases de datos a las que enlaza, SIMBAD y NED, por un lado, y por otro analizamos los dos grandes estándares de catalogación, ISBD consolidada y RDA, y el formato de codificación MARC21.

Sin embargo, debido a la variada tipología documental existente en Astronomía (ver sección 1.1), debemos acotar y precisar la que en este documento se pretende analizar. Las bases de datos NED y SIMBAD han elaborado sendas clasificaciones de objetos celestes disponibles en sus respectivos sitios web (SIMBAD, 2012b; NED, 2012b). Debido a la extensión de ambos listados, la descripción de cada uno de estos objetos sería una tarea prácticamente inabordable en este artículo. Es por esto por lo que, de todos ellos, nos centraremos en aquellos que, formando parte de los listados de SIMBAD y NED, son susceptibles de localizarse como imágenes astrofotográficas en archivos y bibliotecas astronómicas. Dado que NED excluye todos los objetos que se encuentran dentro de nuestra galaxia y que SIMBAD hace lo propio con todos los objetos del Sistema Solar; planetas, satélites, asteroides y cometas quedan excluidos de la clasificación de objetos de estas bases de datos, y por consiguiente de nuestro estudio. Del resto de objetos celestes que sí contienen estas bases de datos, hemos considerado una selección de objetos propuesta por Michael A. Covington en su libro Objetos celestes para telescopios modernos (Celestial objects for modern telescopes) (Covington, 2006), obra recomendada por la Unión Astronómica Internacional (IAU-International Astronomical Union). Así, en general, sólo estrellas, galaxias, cúmulos y nebulosas serán estudiados en este artículo (figura 1). En consecuencia, tampoco es objeto de este estudio la catalogación de cartas/mapas celestes, ya que éstos presentan generalmente amplios conjuntos de objetos, de ahí que su catalogación, notablemente diferente, está siendo abordada en un nuevo trabajo.

Por otra parte, para conocer la información astronómica que permiten describir los estándares MARC21, ISBD consolidada y RDA, primero se ha llevado a cabo una breve revisión del estado actual en el que éstos se encuentran, y se ha establecido una comparación entre los elementos descriptivos exclusivamente de carácter cartográfico que presenta MARC21 (edición de 1999, actualización número 15, septiembre 2012), ISBD consolidada (2011) y RDA (2010), así como las equivalencias entre los tres estándares.

Nuestra aportación, por tanto, se centra en analizar los parámetros más comúnmente empleados por los investigadores en las bases de datos SIMBAD y NED, así como los ofrecidos en Google Sky, que podrían servir para describir una imagen astronómica que contiene un único objeto celeste (o un conjunto reducido de los mismos). Una vez analizados, se indica cuáles de ellos se encuentran presentes en los estándares actuales objeto de estudio en este artículo y cuáles deberían ser incorporados.

Por último, hay que señalar que los parámetros propuestos son, en general, comunes a todos los objetos celestes, salvo algunos en concreto que son específicos de estrellas y/o galaxias. Esto es así debido a que estos parámetros se obtienen como resultado del estudio del espectro de la luz procedente de dichos objetos. 
Figura 1. Ejemplos de los objetos celestes considerados en este artículo: (1) estrella, (2) nebulosa, (3) cúmulo y (4) galaxia. Fuente: DSpace (Repositorio del Instituto de Astronomía de la Universidad de Cambridge), Science Photo Library (imagen de la Royal Astronomical Society) y Observatorio Anglo-Australiano.
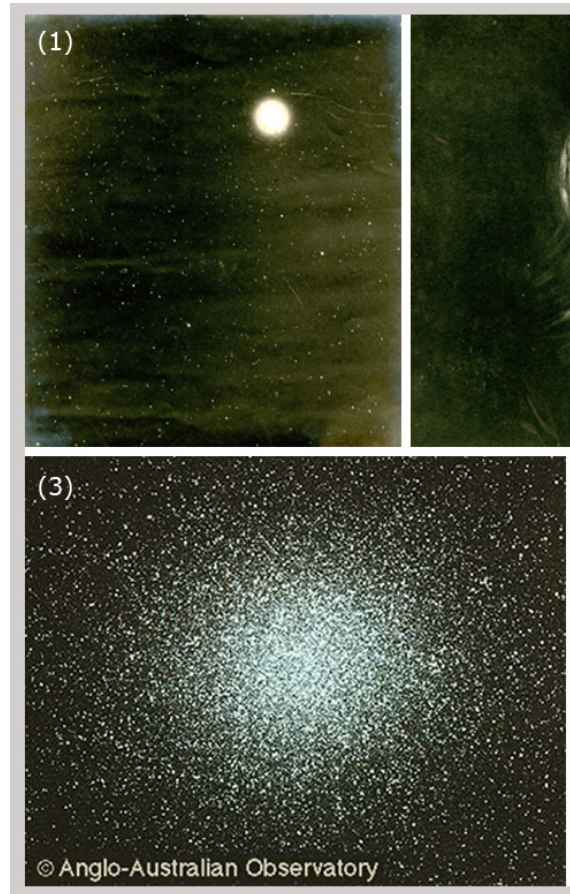

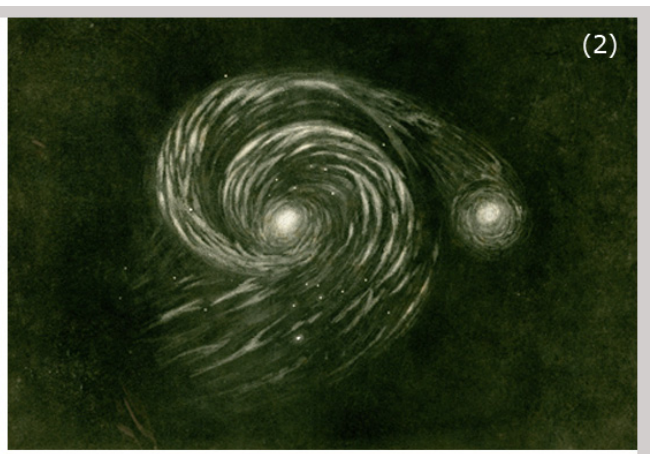

(4)
Así, este artículo está organizado de la siguiente forma: en la sección 3 se presenta la información astronómica que permite describir Google Sky y las bases de datos SIMBAD y NED a las que enlaza, indicando los tipos de búsquedas que se pueden llevar a cabo en ellas, las búsquedas más frecuentes realizadas por los usuarios y los parámetros astronómicos básicos que ofrecen. En la sección 4 se analiza la información que permiten describir los estándares MARC21, ISBD consolidada y RDA, indicando los elementos que contienen para describir recursos astronómicos. A partir de esta información, conociendo lo que podemos describir con estos estándares y los parámetros que nos ofrecen las bases de datos, realizamos una propuesta de incorporación de parámetros en la sección 5.

\section{INFORMACIÓN ASTRONÓMICA QUE OFRECE GOOGLE SKY}

Sky es una herramienta integrada en Google Earth que permite explorar el universo mediante la visualización de imágenes de estrellas, constelaciones, planetas, galaxias, etc., navegar por ellas y seguir sus movimientos en el tiempo y en el espacio (Google Earth, 2012b). Surgió en el año 2005 de la mano de Carol Christian y Alberto Conti, dos miembros del Space Telescope Science Institute (STScI, centro de operaciones del Hubble) (IOPScience, 2008) y actualmente, la última versión disponible de Google Earth es la 6.2, que ofrece dos modalidades: Google Earth, gratuita, y Google Earth Pro, de pago (Google Earth, 2012a). El objetivo de Google Sky es crear un marco general que permita a los usuarios el acceso a las imágenes, catálogos y metadatos del cielo. Dispone de imágenes en el rango del espectro visible, de infrarrojos, rayos $X$ y ultravioleta, además de la posibilidad de superponer estas imágenes tomadas a distintas longitudes onda.

Al hacer clic sobre cualquiera de los objetos celestes, Google Sky facilita la siguiente información astronómica (figura 2):

- Nombre/s del objeto celeste (A). Se proporciona el nombre del objeto celeste en sus distintas versiones según la nomenclatura empleada por diferentes catálogos.

- Información extra de Google (B). El software proporciona cinco enlaces a distintos servicios de Google donde se puede localizar más información sobre cada objeto celeste.

- Ubicación (C). Coordenadas celestes ecuatoriales (ascensión recta y declinación) del objeto celeste seleccionado.

- Distancia (D). Distancia en años luz entre la Tierra y el objeto seleccionado.

- Tipo espectral (E). Conocido también como Clasificación Espectral de Harvard, es la cla- 
sificación estelar más utilizada en Astronomía donde los diferentes tipos se ordenan según la temperatura de la estrella.

- Información técnica $(F)$. Google Sky permite obtener más información del objeto seleccionado haciendo clic en los enlaces a la base de datos SIMBAD y NED (ver secciones 3.1 y 3.2).

Como acabamos de comentar, la información presentada hasta el momento no es la única que puede encontrarse en Google Sky, ya que puede localizarse más información sobre cada objeto celeste haciendo clic sobre los enlaces que nos conducen a las bases de datos astronómicas especializadas SIMBAD y NED.

\subsection{Base de datos SIMBAD}

SIMBAD es una base de datos creada por el Centro de Datos Astronómicos de Estrasburgo (Centre de Données astronomiques de Strasbourg -CDS). "EI CDS define, desarrolla y mantiene servicios para ayudar a los astrónomos a encontrar la información que necesitan de forma rápida, aumentando la riqueza de la información astronómica y, particularmente, la de la información online" (Wenger y otros, 2000).

Que SIMBAD es una de las mejores bases de datos del mundo en Astronomía y Astrofísica no es algo baladí, ya en la década de los 80 comenzaba a ser un referente como fuente bibliográfica en la investigación en Astronomía y Astrofísica (Debois, 1989), y así lo afirmaban R. Shobbrook y F. Genova en la década de los 90: "SIMBAD and its host, the Strasbourg Observatory, needs no introduction. It is probably the best known database in the field of astronomy and has been around as an online service since 1981" (Shobbrook y Genova, 1995). Prueba de ello es el notable incremento de peticiones diarias que ha experimentado la base de datos en los últimos años (Wenger y Oberto, 2010). Actualmente, SIMBAD es un recurso importante dentro de los servicios astronómicos online y de los llamados Observatorios Virtuales (Virtual Observatories -VO-) (Wenger, 2007).

Esta base de datos contiene información sobre estrellas, galaxias, objetos no estelares (nebulosas planetarias, clusters, etc.) y objetos adicionales observados en varias longitudes de onda (radio, infrarrojo, rayos $X$ ). Los únicos objetos que no incluye SIMBAD son el Sol y los cuerpos del Sistema Solar (Wenger y otros, 2000).

\subsubsection{Tipos de búsqueda en SIMBAD}

La interfaz gráfica de usuario de SIMBAD contiene siete secciones: Queries, Documentation, Information, Content, Statistics, Acknowledgment y Basic Search, de las cuales sólo nos interesa la primera, Queries, ya que nos permite realizar diferentes búsquedas para solicitar información a la base de datos (SIMBAD, 2012a):

Búsqueda sencilla (Basic Search). Permite buscar por cualquier campo o parámetro. Pueden introducirse desde nombres de objetos hasta sus propias coordenadas.

Figura 2. Presentación y distribución de la información que ofrece Google Sky de los objetos celestes. Fuente: elaboración propia. Imagen tomada de Google Sky.

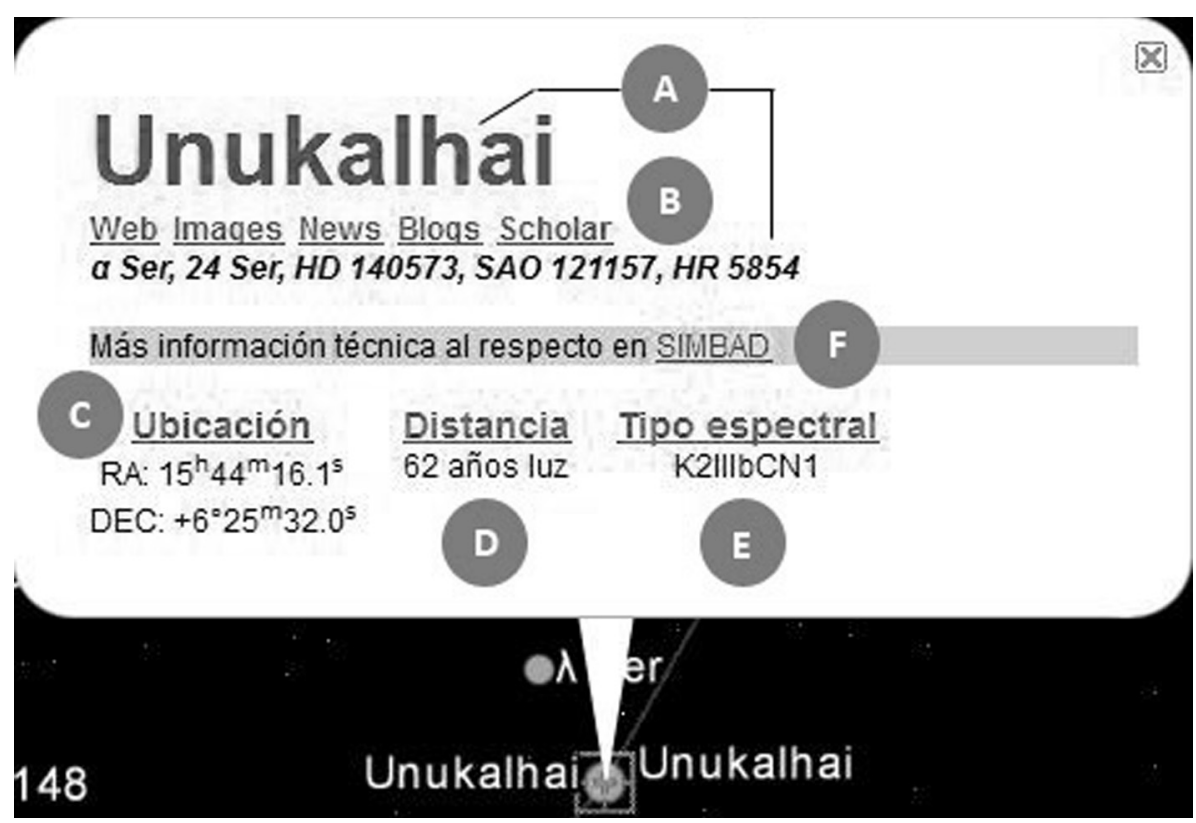


Búsqueda por identificador (By Identifier). Permite buscar por un identificador en concreto (nomenclatura del objeto) o un listado de ellos contenidos en un fichero de texto ASCII con un identificador por línea.

- Búsqueda por coordenadas (By Coordinates). Es posible buscar un objeto o una lista de ellos directamente por sus coordenadas.

- Búsqueda por criterio (By Criteria). Se trata de un sistema algo más avanzado que permite buscar objetos por distintos criterios, desde coordenadas hasta velocidades, incluyendo combinaciones de todos ellos a través de concretas expresiones de búsqueda cuya estructura facilita la base de datos.

- Búsqueda por referencia (Reference query). Permite buscar por referencias bibliográficas (autores, títulos, años, etc.).

- Búsqueda en anotaciones de usuarios (Display all user annotations). Se trata de un servicio mediante el cual es posible recuperar información que los usuarios pueden escribir en la base de datos en forma de posts.

- Búsqueda avanzada por comandos (scripts). Se trata de una forma de búsqueda para usuarios más avanzados mediante la cual se pueden hacer peticiones a través de líneas de comandos combinando los distintos tipos de búsqueda.

\subsubsection{Tipos de búsquedas más realizadas en SIMBAD por los usuarios}

Tal como se ha comentado en la sección 2, este artículo pretende mostrar que existe determinada información astronómica que no se contempla en las normas de catalogación actuales. Si esta hipótesis es correcta, automáticamente surge la pregunta: ¿cuál es esa información?, es decir ¿cuáles son los datos mínimos deseables que es necesario añadir a los registros de este tipo de material para hacerlos más útiles a los investigadores?

Como parece natural, la respuesta a esta pregunta debería ser dada por los propios investigadores. Sin embargo, puesto que resultaría costoso realizar una encuesta a un amplio número de ellos, podemos recurrir a los administradores de las bases de datos para tratar de conocer cuáles son los tipos de búsqueda más frecuentemente realizadas por los usuarios en sus peticiones a la base de datos. Esto nos ofrece una información anónima, y por lo tanto objetiva, de las necesidades de los investigadores.

La figura 3 muestra la distribución porcentual de los tipos de búsquedas más efectuadas en SIMBAD entre los meses de octubre de 2011 y agosto de 2012. Como puede observarse, la búsqueda por comandos (script) es la más utilizada por los usuarios (54\%), lo cual no resulta sorprendente puesto que, como venimos comentando, los usuarios de estas bases de datos suelen ser tan especializados como el material con el que trabajan. Lamentablemente no disponemos de estadísticas relativas a los comandos más empleados dentro de la búsqueda por scripts, sin embargo, si acudimos a la sección de ayuda de la búsqueda por comandos de SIMBAD (SIMBAD, 2012c) podemos observar que puede solicitarse información a la base de datos mediante aquellos parámetros que ésta ofrece de cada objeto celeste, según se indica en la "búsqueda por criterio". El 23\% de las que se realizan son por coordenadas, el $19 \%$ por identificadores, el $2 \%$ por referencias bibliográficas y el restante $2 \%$ que hemos titulado "Miscelánea" incluye búsqueda por imágenes, autores, ejemplos, etc.

\subsubsection{Parámetros astronómicos básicos que ofrece SIMBAD}

Teniendo en cuenta la información proporcionada en la sección Description of the queriable fields

Figura 3. Tipos de búsquedas más frecuentes en SIMBAD. Fuente: Datos proporcionados por cortesía de Marc Wenger, ingeniero del staff de SIMBAD.

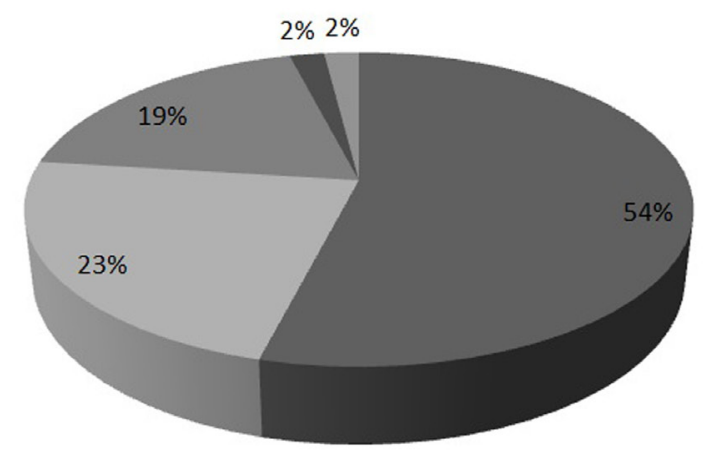

Búsqueda por comandos (script)

Búsqueda por coordenadas

Búsqueda por identificadores

- Búsqueda por referencias bibliográficas

niscelánea 
(SIMBAD, 2012d) y la ofrecida en los registros recuperados al efectuar una búsqueda en la base de datos, presentamos una selección de los campos y/o parámetros mínimos que deben tener los objetos celestes según el criterio de "datos básicos" (basic data) de SIMBAD.

Estos son los parámetros astronómicos básicos que ofrece SIMBAD: coordenadas (coordinates); desplazamiento al rojo (redshifts); distancias (stellar distances); filtros (filtrado en el sistema fotométrico) (filters); flujos (fluxes); magnitud (magnitude); movimiento propio (proper motion); paralaje (parallaxes); tamaño angular (angular size); tipo espectral (spectral type); tipo morfológico (morphological type); y velocidad radial (radial velocity).

\subsection{Base de datos NED}

La segunda gran base de datos que enlaza Google Sky se conoce como NASA/IPAC Extragalactic Database (NED), y está gestionada por la National Aeronautics and Space Administration (NASA) junto con el Infrared Processing and Analysis Center (IPAC). Operativa desde junio de 1990, proporciona una cantidad ingente de datos astronómicos y astrofísicos que cubren todas las longitudes de onda (multiwavelength), además de encontrarse inmersa en un proceso continuo de expansión y revisión que hacen de ella una de las bases de datos de referencia mundial en esta disciplina (Corwin y otros, 1995).

Se trata de un recurso online de investigación diseñado para científicos, docentes, observatorios, etc., centrado principalmente en aportar información sobre objetos exteriores a la Vía Láctea. Su principal objetivo es mantener actualizados todos los datos básicos acerca de objetos extragalácticos (galaxias, nebulosas, etc.), incluyendo referencias a la literatura existente en Astrofísica (Mazzarella y otros, 2001).

\subsubsection{Tipos de búsqueda en NED}

La interfaz gráfica de usuario de la base de datos NED presenta, de forma general, cinco secciones principales: Objects, Data, Literature, Tools e Info, de las que nos interesan las dos primeras. La sección "Objetos" (Objects) permite realizar búsquedas de objetos extragalácticos de ocho formas diferentes:

- Búsqueda por el nombre del objeto (By Name). Permite buscar exclusivamente con el nombre del objeto. NED está preparada para reconocer los distintos nombres más conocidos de cada objeto.

- Búsqueda por nombre cercano al objeto (Near Name). Se puede interrogar al sistema indicando un objeto celeste concreto y un radio (distancia) alrededor del mismo. La base de datos devuelve el objeto buscado junto con todos aquellos objetos que se encuentren dentro del radio especificado.
- Búsqueda de objetos de posición cercana (Near Position). Forma de buscar similar a la anterior empleando unas coordenadas cualesquiera en lugar de un objeto celeste determinado.

- Búsqueda por formato de la UAI (IAU -International Astronomical Union- Format). Permite localizar objetos indicando dichos objetos según las convenciones de la Unión Astronómica Internacional.

- Búsqueda por parámetros (By Parameters All-Sky). Permite buscar por medio de los siguientes parámetros: desplazamiento al rojo o velocidad, densidad de flujo o magnitud, tipo de objeto, por el prefijo del nombre y/o por coordenadas ecuatoriales o galácticas.

- Búsqueda por clasificaciones, tipos y atributos (By Classifications. Types, Attributes). Para encontrar objetos especificando la clasificación, tipo o atributos que poseen. Por ejemplo, se puede buscar por morfología óptica o por clasificación espectral.

- Búsqueda por código de referencia (By Refcode). Recupera los objetos que se encuentran dentro de una referencia bibliográfica específica.

- Búsquedas por notas de objetos (Object Notes). Permite buscar notas de objetos de varios catálogos astronómicos y cientos de artículos.

A diferencia de la sección anterior, en "Datos" (Data) se pueden realizar búsquedas para recuperar "datos detallados" de los objetos (datos de los que no disponen todos los objetos). Podemos diferenciar entre:

- Búsqueda de imágenes por nombre del objeto o por región (Images by Object Name or by Region). Permite buscar por nombres de objetos en la base de datos de imágenes. La búsqueda por región permite encontrar imágenes o mapas de una parte dada del cielo utilizando las herramientas proporcionadas por el IRSA (NASA/IPAC InfraRed Science Archive).

- Fotometría y distribución espectral de energía (Photometry \& SEDs). Con esta opción se pueden buscar datos fotométricos para un objeto dado. Además, NED proporciona gráficos de distribución espectral de energía.

- Espectros (Spectra). Esta opción facilita la búsqueda de archivos de espectros de la NED, y el examen y recuperación de los mismos.

- Desplazamientos al rojo (Redshifts). Permite buscar por desplazamientos al rojo o por velocidades radiales para un objeto dado.

- Desplazamiento al rojo no dependiente de las distancias (Redshift-Independent Distances). 
Para realizar búsquedas por el nombre de un objeto en una lista actualizada por la NED de desplazamientos al rojo no dependientes de las distancias.

- Clasificaciones por nombre de objeto (Classifications by Object Name). Permite buscar por clasificaciones, tipos y otros atributos de varias listas y catálogos para un objeto dado.

- Posiciones (Positions). Para encontrar datos de posición procedentes de varias listas y catálogos para un objeto dado.

- Diámetros (Diameters). Permite buscar por diámetros, relaciones de ejes o ángulos de posición de un objeto concreto.

\subsubsection{Tipos de búsquedas más realizadas en NED por los usuarios}

En la figura 4 se muestran las búsquedas que los usuarios (principalmente investigadores) realizan con más frecuencia a la base de datos. La mayor parte de ellas se llevan a cabo en la sección Objects, es decir se realizan buscando por nombre cercano al objeto (near name), por formato de la UAI (IAU format), por código de referencia (refcode), por notas de objetos (object notes), etc., lo que supone el $26.24 \%$ del total. Sin embargo, sólo la búsqueda por nombre del objeto (by name perteneciente a la sección Objects) supone el $25.97 \%$ del total, que es la más popular de todas, ya que muchos servicios de NED necesitan que se haga una búsqueda por objeto como primer paso antes de ejecutar una más específica. La tercera más realizada es la de diámetros de la sección Data, que es el $11.96 \%$ del total. La última que muestra la figura 4 es la que hemos titulado "Micelánea" $y$, aunque se trata del porcentaje más alto, el
$35.83 \%$, incluye búsquedas de muy diversa índole que se realizan con muy poca frecuencia (espectrales $-0.25 \%$-, por desplazamiento al rojo - $0.04 \%$-, por datos fotométricos $-0.35 \%-$, por distancias $0.17 \%$-, etc.), pero que sumando todos sus porcentajes supone la mayor cantidad porcentual de las búsquedas.

\subsubsection{Parámetros astronómicos básicos que ofrece NED}

Teniendo en cuenta la información proporcionada en la sección NED's WWW Interface Features (NED, 2012c), y la ofrecida en los registros recuperados al efectuar una búsqueda en la base de datos, a continuación se presenta una selección de los campos y/o parámetros mínimos que deben tener los objetos celestes según el criterio de "datos básicos" (basic data) de NED.

Los parámetros astronómicos básicos que ofrece NED son: coordenadas (coordinates); desplazamiento al rojo (redshift); diámetros físicos y angulares (angular and physical diameters); espectro (spectra); fotometría y luminosidad (photometry and luminosity); magnitud y filtros (magnitude and filters); tipo de objeto (object type); tipo mofológico (morphological type); y velocidad radial (radial velocity).

\section{INFORMACIÓN ASTRONÓMICA QUE PERMITE DESCRIBIR MARC21, ISBD CONSOLIDADA Y RDA}

En esta sección se realiza un análisis comparativo entre los elementos descriptivos de carácter cartográfico celeste que presentan MARC21, ISBD consolidada y RDA. Para llevar a cabo el análisis se ha realizado una tabla en la que se presentan los

Figura 4. Tipos de búsquedas más frecuentes en NED. Fuente: Datos proporcionados por cortesía de Olga Pevunova y Rick Ebert, ambos staff de NED.

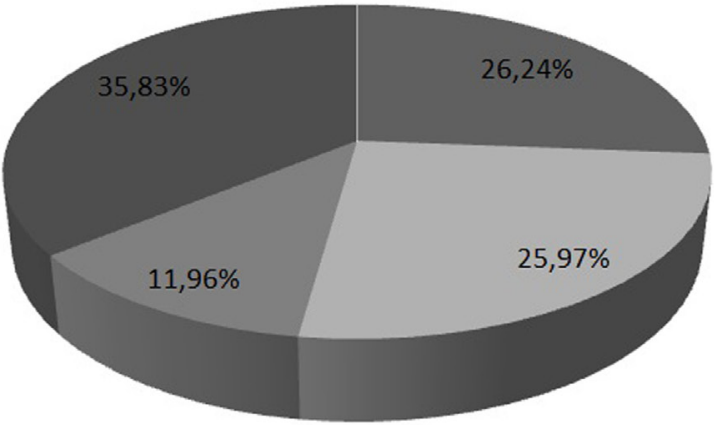

- Búsqueda por las opciones de la sección "Objects"

Búsqueda por nombre del objeto

("By Name" de la sección "Objects")

Búsqueda de diámetros

("Diameters"de la sección "Data")

- Miscelánea 
elementos de dichos estándares que permiten catalogar una imagen celeste (tabla I) donde pueden observarse sus equivalencias y divergencias. Una vez conocida esta información, se ha elaborado un listado con el número total de parámetros astronómicos que permiten describir en su conjunto los tres estándares, con objeto de analizar tres aspectos concretos de los mismos (tabla II):

- Elementos que permiten describir. Es decir, si la norma contempla el parámetro como elemento descriptivo en el registro bibliográfico. En dicha tabla se observa que prácticamente los tres estándares permiten describir los mismos parámetros. Concretamente sólo el formato MARC21 permite describir distancia desde la Tierra y nombre del cuerpo extraterrestre (que solamente se puede indicar si las coordenadas introducidas en el campo 034 no se refieren a una entidad de la Tierra), y sólo ISBD consolidada y RDA permiten describir magnitud.

- Elementos que definen. Se trata de conocer si la norma define el concepto del parámetro. Creemos que es importante que los estándares de catalogación definan los conceptos de los datos que se pueden describir, para facilitar la comprensión de los mismos al catalogador, resultando así más sencilla la tarea de descripción del recurso astronómico. En este sentido, RDA cuida bastante este aspecto, presentando un apartado scope (alcance) en cada elemento descrito (a excepción de la escala angular). Sin embargo, MARC21 tan sólo define los elementos distancia desde la Tierra y nombre del cuerpo extraterrestre (ambos elementos incorporados en una actualización del año 2006). Por su parte, ISBD define varios de estos conceptos en su glosario.

- Elementos que indican cómo estos parámetros deben ser registrados. Esto es, si la norma explica cómo debe registrarse dicho parámetro en el registro bibliográfico. En general MARC21, ISBD consolidada y RDA explican cómo debe registrarse la información de sus elementos, pero encontramos algunas excepciones curiosas, tales como escala angular y distancia desde la Tierra en el formato MARC21, así como magnitud en el caso de ISBD consolidada y RDA.

Tradicionalmente, los estándares de catalogación y codificación han creado un área de datos matemáticos cartográficos en la que han agrupado los datos de descripción técnicos; "Cartographic Mathematical Data" (MARC 21), "Mathematical Data Area" (ISBD(CM)), "Mathematical data (Cartographic resources)" (ISBD consolidada), mientras que RDA presenta todos los elementos descriptivos en el capítulo 7 (Describing Content). En dichos grupos se han incluido elementos descriptivos referidos al soporte que contiene las imágenes o datos astronómicos, tales como la escala angular o la proyección, y otros referidos a las características del objeto celeste en sí, tales como el nombre del objeto, las coordenadas, la magnitud del objeto, la distancia en años luz, la época y el equinoccio. Puede observarse, por tanto, que los estándares se han centrado principalmente en describir datos puramente cartográficos, aunque se aprecia también un esfuerzo por describir el contenido del recurso. Creemos que ese esfuerzo debe tener continuidad, permitiendo una mejora en la descripción técnica de los recursos así como de la recuperación de información científica.

Finalmente, hay que mencionar que el elemento magnitud merece especial atención, ya que es un parámetro astronómico fundamental para la descripción de este tipo de recursos; y vemos que MARC21 no permite describirlo (a no ser que se indicara en un campo de notas), y que ISBD consolidada y RDA ni lo definen, ni indican cómo registrar dicha información. Además, parece que los estándares no le otorgan el honor de ser un dato mínimo deseable, ya que ISBD lo menciona en el campo notas (7.3.1.1) y RDA en la sección Otros detalles de contenido cartográfico (7.27). Si no se define el elemento y tampoco se indica cómo reflejar dicha información en la descripción, el catalogador seguramente pasará por alto este elemento. Con el campo magnitud parece que ISBD quiere referirse a la magnitud aparente de un objeto celeste, pero ni lo dice así "magnitud aparente", ni especifica de forma correcta el valor máximo de dicha magnitud, puesto que los objetos más débiles observados por el telescopio espacial Hubble puede presentar hasta magnitud 30 (Molla, 2009; Astro.uchile, 2012; Wikipedia, 2012) mientras ISBD establece como tope 22.

\section{RESULTADOS. PROPUESTA DE LOS CAMPOS MÍNIMOS DESEABLES PARA LA CATALOGACIÓN DE IMÁGENES CON OBJETOS CELESTES}

A partir de los datos obtenidos en el análisis de Google Sky y las bases de datos astronómicas SIMBAD y NED, se indican los parámetros mínimos deseables para la descripción de objetos celestes, concretamente, estrellas, galaxias, cúmulos y nebulosas, así como la importancia que tiene la inclusión de los mismos en los estándares de catalogación y codificación:

Parámetro 1. Nombre del objeto. A pesar de tratarse de un dato que podría quedar registrado en algunos campos de los estándares actuales (por ejemplo en el campo "título" cuando la imagen celeste tiene como título el propio nombre del objeto que contiene), consideramos que se trata de un campo técnico que debería añadirse a los estándares por tratarse del dato estrella en las búsquedas realizadas. En el año 2006 MARC21 incorporó el campo "Nombre del cuerpo extraterrestre", sin embargo, éste solo es de aplicación cuando las co- 
ordenadas indicadas en el registro se refieren a un cuerpo celeste diferente a la Tierra.

Parámetro 2. Tipo de objeto. Gran cantidad de búsquedas se realizan atendiendo al tipo de objeto (galaxias, nebulosas, estrellas, etc.). Generalmente los nombres técnicos de los objetos están formados por un conjunto de caracteres alfanuméricos. Las letras representan la abreviatura del catálogo al que pertenece el objeto en cuestión, y éstas vienen acompañadas de un número ordinal que clasifica el objeto (Arranz, 2004). Por ejemplo, la conocida galaxia de Andrómeda recibe nombres como "M31", donde la letra "M" indica que se trata de un objeto celeste procedente del catálogo "Messier" y "31" es el número que le asigna este catálogo a dicha galaxia; igualmente ocurre con otro de los nombres que recibe dicha galaxia "NGC224".

Parámetro 3: Otro tipo de coordenadas celestes. Aunque ISBD permite que se indiquen las coordenadas geográficas de cualquier punto situado sobre la superficie de otros cuerpos celestes distintos a la Tierra (por ejemplo la Luna o Marte), las únicas coordenadas celestes que podemos indicar en la normativa vigente son la ascensión recta y la declinación (coordenadas ecuatoriales). Sin embargo, en Astronomía, las coordenadas ecuatoriales no son las únicas presentes. Concretamente, SIMBAD y NED muestran hasta otros seis tipos de coordenadas celestes más: coordenadas eclípticas, coordenadas galácticas, coordenadas supergalácticas, coordenadas ICRS, coordenadas FK4 y coordenadas FK5.

Parámetro 4. Distancia al objeto. Se trata de un parámetro tomado en consideración por MARC21 en el año 2006, pero no por el resto de los estándares aquí mencionados. Sin embargo, MARC define esta distancia en años-luz, obviando otro tipo de unidades de medida muy empleados por astrónomos como el pársec o la unidad astronómica.

Parámetro 5. Tipo morfológico. Como su propio nombre indica, tiene que ver con la forma de los objetos observados. Esta información permite también clasificar dichos objetos, aunque se emplea principalmente para catalogar galaxias (Astronomía Moderna, 2010).

Parámetro 6. Diámetros físicos y angulares (dimensiones). Conocer las dimensiones de los objetos celestes permite a los astrónomos poder clasificarlos en determinados grupos. Por ejemplo, en el caso de una galaxia elíptica es necesario conocer las dimensiones de sus semiejes mayor y menor.

Parámetro 7. Desplazamiento al rojo. Se trata de un parámetro de gran importancia en Astrofísica puesto que, entre otras informaciones, permite a los científicos saber si los objetos observados se acercan o se alejan de nosotros además de estimar distancias a dichos objetos.

Parámetro 8. Velocidad radial. Parámetro relacionado con el desplazamiento al rojo que permite estimar masas de las estrellas e incluso detectar planetas alrededor de estrellas (Centro de Astrofísica da Universidade do Porto, 2012).

Parámetro 9. Movimiento propio. Se trata de una forma de medir la velocidad transversal de un objeto celeste (velocidad en dirección perpendicular a la velocidad radial). Está relacionado con la velocidad radial y el desplazamiento al rojo y, entre otras informaciones, da una idea de la distancia al objeto considerado (McKee, 2005; Reid, 2002).

Parámetro 10. Paralaje. Medida alternativa empleada para el cálculo de distancias. Cuando éstas son muy grandes se emplean las conocidas paralajes espectroscópicas (relacionadas con el tipo espectral y la magnitud absoluta), paralajes dinámicas (aplicando las leyes de Kepler a sistemas binarios) o paralajes cinemáticas (relacionadas con el movimiento propio y la velocidad radial) (Alfonso-Garzón y otros, 2009).

Parámetro 11. Magnitudes de brillo (Fotometría). La Fotometría es la rama de la Astronomía que se dedica a medir el brillo de los objetos celestes. La medida de dicho brillo permite clasificar los objetos observados (Alfonso-Garzón y otros, 2009). Existen distintos métodos para realizar fotometría dependiendo de los filtros empleados para realizar las mediciones.

Parámetro 12. Tipo espectral. Permite clasificar estrellas según el espectro de luz que se recibe de ellas. Ello posibilita una comprensión profunda de la composición química de la estrella, temperatura, masa, etc. (Alfonso-Garzón y otros, 2009).

Parámetro 13. Clase de luminosidad. Se trata de una forma de clasificación de estrellas complementaria a la anterior teniendo en cuenta cómo afecta la gravedad de la superficie de la estrella y su temperatura a las líneas espectrales. Este parámetro permite conocer la densidad de las estrellas y diferenciar entre tamaños de estrellas que presentan espectros similares según su temperatura. (Alfonso-Garzón y otros, 2009).

Parámetro 14. Longitud(es) de onda de la imagen. No todas las imágenes de objetos celestes están tomadas en el rango del espectro visible, tal y como se comentó en la sección 1.1. En efecto, muchas de estas imágenes nos muestran cómo se vería el objeto en otras longitudes de onda (o simultáneamente en varias de ellas) proporcionando valiosa información imperceptible al ojo humano. 
Tabla I. Equivalencias y divergencias entre los elementos para describir recursos astronómicos que presentan MARC21, ISBD consolidada y RDA.

\begin{tabular}{|c|c|c|}
\hline $\begin{array}{l}\text { MARC } 21 \\
\text { (edición de 1999, actualización } \\
\text { número 15, septiembre 2012) }\end{array}$ & ISBD Consolidada (2011) & RDA (2010) \\
\hline $\begin{array}{l}034 \text { - Datos matemáticos cartográficos } \\
\text { codificados }(R)\end{array}$ & --- & --- \\
\hline \$h - Escala Angular (R) & --- & --- \\
\hline \$j - Declinación-límite septentrional (NR) & --- & --- \\
\hline \$k - Declinación-límite meridional (NR) & --- & --- \\
\hline \$m - Ascensión recta-límite oriental (NR) & --- & --- \\
\hline \$n - Ascensión recta-límite occidental (NR) & --- & --- \\
\hline $\begin{array}{l}\$ p \text { - Equinoccio (NR) } \\
\text { Equinoccio o época de un mapa celeste. }\end{array}$ & --- & --- \\
\hline$\$ r$ - Distancia desde la tierra (NR) & --- & --- \\
\hline $\begin{array}{l}\$ z-\text { Nombre del cuerpo extraterrestre } \\
(N R)\end{array}$ & --- & --- \\
\hline 255 - Datos matemáticos cartográficos (R) & $\begin{array}{l}\text { 3.1. Datos matemáticos (Recursos } \\
\text { Cartográficos) }\end{array}$ & --- \\
\hline$\$ a-$ Escala (NR) & $\begin{array}{l}\text { 3.1.1 Declaración de escala (obligatorio si } \\
\text { es aplicable) } \\
\text { 3.1.1.9 La escala para las cartas celestes } \\
\text { se expresa como una escala angular en } \\
\text { milímetros por grado. }\end{array}$ & $\begin{array}{l}\text { 7.25.1.5 Escala no lineal } \\
\text { Registra la declaración de escala } \\
\text { para una imagen, mapa etc., con } \\
\text { una escala no lineal (por ejemplo, } \\
\text { cartas celestes }[\ldots]) \text {. }\end{array}$ \\
\hline \$b - Proyección (NR) & 3.1.2 Declaración de proyección & $\begin{array}{l}\text { 7.26 Proyección del Contenido } \\
\text { Cartográfico }\end{array}$ \\
\hline$\$ c$ - Coordenadas (NR) & $\begin{array}{l}\text { 3.1.3. Declaración de coordenadas y } \\
\text { equinoccio } \\
\text { 3.1.3.2 Mapas de otros cuerpos celestes } \\
\text { como la Luna de la Tierra, pueden tener } \\
\text { coordenadas registradas apropiadas al } \\
\text { sistema de coordenadas del cuerpo celeste } \\
\text { dado. }\end{array}$ & $\begin{array}{l}\text { 7.4 Coordenadas del Contenido } \\
\text { Cartográfico }\end{array}$ \\
\hline $\begin{array}{l}\text { \$d - Zona (NR) } \\
\text { Utilizado para las cartas celestes. }\end{array}$ & 3.1.3.3 Ascensión recta y declinación & 7.4.4 Ascensión recta y declinación \\
\hline $\begin{array}{l}\text { \$e - Equinoccio (NR) } \\
\text { Mención del equinoccio o época. }\end{array}$ & $\begin{array}{l}\text { 3.1.3. Declaración de coordenadas y } \\
\text { equinoccio } \\
\text { 3.1.3.4 Equinoccio ([...] la declaración de } \\
\text { equinoccio }[\ldots] \text { la declaración de época }[\ldots] \text { ) }\end{array}$ & $\begin{array}{l}\text { 7.5. Equinoccio } \\
7.6 \text { Época }\end{array}$ \\
\hline--- & $\begin{array}{l}\text { 7.3. Notas sobre material o tipo de recurso } \\
\text { de un área específica } \\
\text { 7.3.1.1 Para cartas celestes, la primera } \\
\text { nota está relacionada con la nota magnitud. }\end{array}$ & $\begin{array}{l}7.27 \text { Otros detalles del Contenido } \\
\text { Cartográfico } \\
\text { Para contenido cartográfico celeste, } \\
\text { registrar la magnitud del contenido } \\
\text { cartográfico. }\end{array}$ \\
\hline
\end{tabular}

Nota: Traducción propia. La información original de las normas está en inglés. 
Tabla II. Análisis de los parámetros astronómicos que permiten describir (C), que definen (F) y que indican cómo registrar (R) MARC21, ISBD consolidada y RDA.

\begin{tabular}{|c|c|c|c|c|}
\hline $\begin{array}{c}\text { Parámetros astronómicos } \\
\text { presentes en los } \\
\text { estándares }\end{array}$ & Aspectos analizados & MARC 21 & $\begin{array}{c}\text { ISBD } \\
\text { Consolidada }\end{array}$ & RDA \\
\hline \multirow{3}{*}{$\begin{array}{l}\text { Ascensión recta y } \\
\text { declinación (coordenadas } \\
\text { celestes ecuatoriales) }\end{array}$} & $\mathrm{C}$ & $x$ & $x$ & $x$ \\
\hline & $\mathrm{F}$ & & $x$ & $x$ \\
\hline & $\mathrm{R}$ & $x$ & $x$ & $x$ \\
\hline \multirow{3}{*}{ Distancia desde la Tierra } & $\mathrm{C}$ & $x$ & & \\
\hline & $\mathrm{F}$ & $x$ & & \\
\hline & $\mathrm{R}$ & & & \\
\hline \multirow{3}{*}{ Época } & $\mathrm{C}$ & $x$ & $x$ & $x$ \\
\hline & $\mathrm{F}$ & & $x$ & $x$ \\
\hline & $\mathrm{R}$ & $x$ & $x$ & $x$ \\
\hline \multirow{3}{*}{ Equinoccio } & $\mathrm{C}$ & $x$ & $x$ & $x$ \\
\hline & $\mathrm{F}$ & & $x$ & $x$ \\
\hline & $\mathrm{R}$ & $x$ & $x$ & $x$ \\
\hline \multirow{3}{*}{ Escala angular } & $\mathrm{C}$ & $x$ & $x$ & $x$ \\
\hline & $\mathrm{F}$ & & & \\
\hline & $\mathrm{R}$ & & $x$ & \\
\hline \multirow{3}{*}{ Magnitud } & $\mathrm{C}$ & & $x$ & $x$ \\
\hline & $\mathrm{F}$ & & & \\
\hline & $\mathrm{R}$ & & & \\
\hline \multirow{3}{*}{$\begin{array}{l}\text { Nombre del cuerpo } \\
\text { extraterrestre }\end{array}$} & C & $x$ & & \\
\hline & $\mathrm{F}$ & $x$ & & \\
\hline & $\mathrm{R}$ & $x$ & & \\
\hline \multirow{3}{*}{ Proyección } & $\mathrm{C}$ & $x$ & $x$ & $x$ \\
\hline & $\mathrm{F}$ & & $x$ & $x$ \\
\hline & $\mathrm{R}$ & $x$ & $x$ & $x$ \\
\hline
\end{tabular}

Nota: C: Describir (parámetros que permite describir la normativa); F: Definir (parámetros que define conceptualmente); R: Registrar (parámetros cuya información se indica cómo debe ser registrada). Celda con X: Sí; Celda vacía: No. 


\section{CONCLUSIONES}

Con este estudio ha quedado reflejado que existen gran cantidad de parámetros astronómicos disponibles y accesibles en Internet a través de bases de datos astronómicas como SIMBAD y NED, y de software como Google Sky, que no aparecen recogidos en los estándares de catalogación y codificación vigentes analizados, y que se pueden tener en cuenta para mejorar la descripción de recursos astronómicos. Así lo atestiguan la gran cantidad de peticiones que se realizan a diario a estas bases de datos empleando dichos parámetros como elementos de consulta. Son estos parámetros, por tanto, candidatos a convertirse en futuros campos de descripción. En este sentido, pensamos que nuestra aportación de parámetros astronómicos (sección 5) puede ayudar a completar la descripción documental de estrellas, galaxias, nebulosas y cúmulos presentes en las imágenes astrofotográficas de archivos y bibliotecas astronómicas.

Aunque por parte de las bibliotecas y asociaciones encargadas de la elaboración de dichos estándares se ha hecho un gran esfuerzo para describir de forma general el universo bibliográfico, creemos que hay que seguir avanzando pero hacia una descripción mucho más especializada, preguntándonos, al igual que Picco y Ortiz-Repiso (2012), "si el modelo vigente de la catalogación, que propone dar respuesta desde un único código al variado universo bibliográfico, es el adecuado"; ya que vivimos en un mundo altamente especializado donde constantemente se genera documentación especializada, que debe permitir a su vez realizar búsquedas muy especializadas. En efecto, tal y como se ha mostrado en la sección 3.1.1., ahora los usuarios pueden estar interesados no sólo por recuperar determinada información de un objeto celeste, sino, por ejemplo, en conseguir todos aquellos objetos que, teniendo un desplazamiento al rojo comprendido entre dos valores, se encuentren a una determinada distancia de la Tierra. En definitiva, nuestro objetivo es que los usuarios puedan buscar en el OPAC de las instituciones documentales de forma similar a como lo hacen en una base de datos especializada. Creemos, por tanto, que sólo mediante una descripción profunda de los recursos astronómicos se conseguirá esta satisfactoria recuperación de información científica.

\section{AGRADECIMIENTOS}

Este trabajo ha sido posible gracias a la financiación de la Fundación Séneca (Agencia Regional de Murcia de Ciencia y Tecnología) y es uno de los resultados de proyecto ARGOS II, con referencia 11936/PHCS/09.

Agradecemos a los revisores sus comentarios a las versiones anteriores de este artículo. Aprovechamos también para dar las gracias a todas las personas que han contribuido a este trabajo. Marc Wenger, Sébastien Derriere y François Bonnarel, miembros del staff de la base de datos SIMBAD ${ }^{1}$. Olga Pevunova y Rick Ebert, miembros del staff de la base de datos NED². Jenny Higham, bibliotecaria y archivera de la Royal Astronomical Society y Mark Hurn, bibliotecario del Instituto de Astronomía de la Universidad de Cambridge. Enrique Solano Márquez, investigador principal del proyecto Observatorio Virtual Español. Mary Larsgaard, jefa de la sección Map and Imagery Laboratory de la biblioteca de la Universidad de California y Paige G. Andrew, bibliotecario del Departamento Cataloging and Metadata Services de la Biblioteca de la Universidad de Pennsylvania. Elena Escolano Rodríguez, jefa de la Unidad de Normalización del Área de Patrimonio de la Subdirección General de Publicaciones y Patrimonio Cultural del Ministerio de Defensa español. Francisco José González González, director técnico de la Biblioteca y el Archivo Histórico del Real Instituto y Observatorio de la Armada Española (ROA). José Manuel Vaquero, profesor del Departamento de Física Aplicada de la Escuela Politécnica de la Universidad de Extremadura. Francisco Javier Molero Madrid, ingeniero de telecomunicaciones y doctorando en Astrodinámica y Mecánica Celeste del Departamento de Matemática Aplicada de la Universidad de Murcia.

Finalmente, agradecer también a Harriet Brighton sus revisiones y correcciones de la traducción inglesa del texto y al resto de personas que han contribuido de alguna manera a la realización de este trabajo.

\section{NOTAS}

[1] La base de datos sugiere que se redacte el agradecimiento incluyendo esta frase en el artículo (This research has made use of the SIMBAD database, operated at CDS, Strasbourg, France).

[2] La base de datos sugiere que se redacte el agradecimiento incluyendo esta frase en el artículo: (This research has made use of the NASA/IPAC Extragalactic Database (NED) which is operated by the Jet Propulsion Laboratory, California Institute of Technology, under contract with the National Aeronautics and Space Administration).

\section{BIBLIOGRAFÍA}

Accomazzi, A. (2010). Astronomy 3.0 Style. En: Isaksson, $\mathrm{E}$ [et al]. (editores). Library and Information Services in Astronomy IV. San Francisco: Astronomical Society of the Pacific Conference Series, vol. 33, 273-281.

Alfonso-Garzón, J; Baladí-Enríquez, D.; Morales Durán, C. (coords.) (2009). 100 conceptos básicos de astronomía. Madrid: Ministerio de Defensa; Sociedad Española de Astronomía; Instituto de Técnica Aeroespacial Esteban Terradas. 102 p. [Consulta: 16/10/2012]. Disponible en: <http:// www.sea-astronomia.es/drupal/sites/default/files/ archivos/100\%20Conceptos\%20Astr.pdf >

Andrew, P. G. (2011). RDA and cartographic materials: mapping a new route. Association for Library Collections and Technical Services Webcast. 
[Consulta: 13/10/2012]. Disponible en: <http:// www.ala.org/alcts/confevents/upcoming/webinar/ cat/092811>

Anglo-Australian Observatory. Cúmulo globular NGC 5139. [Consulta: 11/11/2012]. Disponible en: <http://spider.seds.org/ngc/ngc.cgi?NGC+5139>

Arranz, P (2004). Guía de campo de las constelaciones. Madrid: Equipo Sirius, 559 p.

Astro.uchile (2012). Glosario. Departamento de Astronomía. Universidad de Chile. [Consulta: 16/10/2012]. Disponible en: <http://www.astro. uchile.cl/glosario/glosario.htm>

Astronomía Moderna (2010). Morfología de las galaxias. [Consulta: 11/11/2012]. Disponible en: <http://www.astronomiamoderna.com.ar/2011/ morfologia-de-las-galaxias/>

Bhattacharjee, Y. (2009). Stars in dusty filing cabinets. Science Magazine, vol. 324, 460-461. [Consulta: 10/09/2012]. Disponible en: <http://www.pari. edu/library/ScienceMagazineApr2009archival\%20 astronomy.pdf>

BrandZTM Top 100 Most Valuable Global Brands 2012 (2012). [Consulta: 1/06/2012]. Disponible en: <http://www.millwardbrown.com/brandz/2012/ Documents/2012_BrandZ_Top100_Chart.pdf>

Centro de Astrofísica da Universidade do Porto (2012). Expresso. [Consulta: 11/11/2012] Disponible en: <http://espresso.astro.up.pt/>

Corwin, H. G. y otros (1995). The NASA/IPAC Extragalactic Database: A status report. Astro Lett. and Communications, vol. 31, 9. [Consulta: 22/08/2011]. Disponible en: <http://articles.adsabs. harvard.edu/cgi-bin/nph-iarticle_query?1995ApL\%2 6C. .31....9C\&defaultprint $=$ YES\&filetype $=$. pdf $>$

Covington, M. A (2006). Astronomía práctica para principiantes: objetos celestes para telescopios modernos. Madrid: Akal. $271 \mathrm{p}$.

Debois, P (1989). SIMBAD bibliography and other astronomical bibliographies. Library \& Info. Services Astronomy, IAU Coll.110, 150-153. [Consulta: 21/08/2011]. Disponible en: <http://articles.adsabs. harvard.edu/cgi-bin/nph-iarticle_query?1989lisa.con f..150D\&defaultprint $=$ YES\&filetype $=$. pdf $>$

Durán Guardeño, A.J. (2012). Newton. La ley de la gravedad. La fuerza más atractiva del universo. Grandes ideas de la ciencia. Navarra: RBA coleccionables, $167 \mathrm{p}$.

DSpace. Images from the Institute of Astronomy Library. [Consulta: 12/11/2012]. Disponible en: <http://www.dspace.cam.ac.uk/handle/1810/214761>

Erway, R. (2012). Increasing Access to Special Collections. Liber Quarterly, vol. 21 (2), January, 294-307.

Escolano Rodríguez, E. (2011). Estado de la cuestión de ISBD. VII Encuentro Internacional y III Nacional de Catalogadores "Estándares y procedimientos para la organización de la información", p. 1-16. [Consulta: 26/09/2012]. Disponible en: <http:// www.bn.gov.ar/descargas/catalogadores/encuentro2011/ponencia-23-B-EscolanoRodriguez.pdf>

Estivill-Rius, A. (2011). Resource, description and access, RDA. Un nuevo retraso para preparar mejor el cambio. El profesional de la información, noviembre-diciembre, vol. 20 (6), 694-700.
Google Earth (2012a). Página web principal. [Consulta: 10/05/2011]. Disponible en: <http://www.google. es/intl/es/earth/index.html>

Google Earth (2012b). Sky en español. [Consulta: 9/05/2012]. Disponible en: <http://www.googlesky.es/>

Grothkopf, U. (2011). Astronomy libraries - Your gateway to information. En: Sterken, S. Scientific writing for young astronomers. EAS Publications Series, p. 91-118. [Consulta: 20/10/2012]. Disponible en: <http://www.eso.org/sci/libraries/ articles/SWYA/grothkopf-20110111.pdf>

Heck, A. (1993). The increasing rôle of librarians in astronomical information retrieval. Bull. Inform. CDS, (42), 51-55.

Hernández Cervantes, L.; Santillán González, A.; González-Ponce, A. R (2009). Observatorios virtuales astrofísicos. Revista Digital Universitaria UNAM. [Consulta: 22/08/2011]. Disponible en: $<$ http://www.oei.es/divulgacioncientifica/reportajes029.htm>

IFLA (2012). ISBD namespaces published. Disponible en: <http://www.ifla.org/news/isbd-namespacespublished $>$

IOP Science (2008). Interview: How Google conquered the sky. Physics Education, vol. 43 (3), 323-325. [Consulta: 11/05/2011]. Disponible en: <http://iopscience.iop.org/0031-9120/43/3/M02/ pdf/0031-9120_43_3_M02.pdf>

ISBD. International Standard Bibliographic Description. Consolidated edition (2011). IFLA. Series on bibliographic control, vol. 44. Alemania: De Gruyter Saur, $284 \mathrm{p}$.

Kalf, R. (2008). FRBR: an opportunity for map collections and map users? Liber Quarterly, vol. 18 (2), 276-291.

Kanas, N. (2009). Star maps: history, artistry and cartography. $2^{a}$ ed. Alemania: Praxis, 416 p.

Kumar Rai, V. (2010). Virtual library: an evolution of online astronomy and astrophysics resources for astronomers. En: Isaksson, $\mathrm{E}$ [et al]. (editores). Library and Information Services in Astronomy IV. San Francisco: Astronomical Society of the Pacific Conference Series, vol. 33, p. 348-352.

Lachièze-Rey, M.; Luminet, J-P. (2001). Celestial treasury. From the music of the spheres to the conquest of space. Laredo, J (trad.). Madrid: Cambridge University Press, 207 p.

Lagerstrom, J.; Grothkopf, U. (2010). Astronomy Librarian - Quo vadis?. Future Professional Communication in Astronomy II, p. 110-118. [Consulta: 7/10/2012]. Disponible en: <http:// arxiv.org/pdf/1104.1184v1.pdf>

Larsgaard, M. L. (2007). FRBR and cartographic materials: mapping out FRBR. En: Taylor, Arlene G. (ed). Understanding FRBR: what it is and how it will affect our retrieval tools. Libraries Unlimited.

Library of Congress (2012a). Bibliographic Framework as a Web of Data: Linked Data Model and Supporting Services (November 21, 2012). [Consulta: 9/01/2013]. Disponible en: <http://www.loc.gov/ marc/transition/>

Library of Congress (2012b). MARC Standards. [Consulta: 3/11/2012]. Disponible en: <http:// www.loc.gov/marc/marc.html> 
MARC 21 format for bibliographic data (2012), Library of Congress. [Consulta: 3/11/2012]. Disponible en: <http://www.loc.gov/marc/bibliographic/>

Mazzarella, J. M. [etal] (2001). Capabilities of the NASA/ IPAC Extragalactic Database in the Era of a Global Virtual Observatory. En: STARCK, J y MURTAGH, F. D. (eds). Proceedings of SPIE: Astronomical Data Analysis, vol. 4477, 1-15 (en prensa). [Consulta: 22/05/2011]. Disponible en: <http://cdsweb.cern. ch/record/526371/files/0111200.pdf>

Mc Cool, M. (2009). Touring the cosmos through your computer: a guide to free desktop planetarium software. CAPjournal, (7), 21-23. [Consulta: 1/08/2011]. Disponible en: <http://outreach. as.utexas.edu/marykay/highschool/07_21.pdf>

McEathron, S. R. (2002). Cartographic materials as Works. Cataloging \& Classification Quarterly, vol. 33 (3-4), 181-191.

McKee, M. (2005). Distant galaxy's subtle sidling measured. NewScientist. [Consulta: 11/11/2012]. Disponible en: <http://www.newscientist.com/ article/dn7095>

McNally, D. (2001). A particular example of a general problem. Astronomy \& Geophysics, vol. 42 (3), 3.8.

Molla, M. (2009). Magnitud [en línea]. Sociedad Española de Astronomía. [Consulta: 14/11/2012]. Disponible en: <http://www.sea-astronomia.es/ drupal/node/253>

Morse, T. (2012). Mapping relationships: examining bibliographic relationships in sheet maps from Tillett to RDA. Cataloging and Classification Quarterly, vol. 50(4), 225-248.

NED (2012a). Página web principal [Consulta: 22/08/2011]. Disponible en: <http://ned.ipac. caltech.edu/>

NED (2012b). Advanced All-Sky Search For Objects By Parameters. [Consulta: 22/10/2012]. Disponible en: <http://ned.ipac.caltech.edu/forms/byparams. html>

NED (2012c). NED's WWW Interface Features [en línea]. [Consulta: 5/11/2012]. Disponible en: $<$ http://ned.ipac.caltech.edu/help/allfeats.html>

Picco, P. (2007). RDA: el alcance internacional del nuevo Código de Catalogación. TransInformação, 19 (3), 219-226.

Picco, P.; Ortiz Repiso, V. (2012). RDA, el nuevo código de catalogación: cambios y desafíos para su aplicación. Revista Española de Documentación Científica, vol. 35, 145-173.

ProEspacio (2011). Explotación de datos científicos. Calculando por las nubes... InfoEspacio, (21), 12-18.

RDA, resource, description and access (2010). American Library Association, Canadian Library Association, CILIP.

Reid, N (2002). Proper motion selection of candidate nearby dwarfs. [Consulta: 10/11/2012]. Disponible en: <http://www-int.stsci.edu/ inr/nstars2.html>

Rivera, A. (2012). Dos estrellas para verificar a Einstein. El País. 4 oct. 2012. [Consulta: 10/10/2012]. Disponible en: <http:// sociedad.elpais.com/sociedad/2012/10/04/ actualidad/1349371913_495108.html>

Royal Astronomical Society (RAS) (2012). Library. [Consulta: 25/10/2012]. Disponible en: <http:// www.ras.org.uk/library>
Sainz, J. (2012). Formato MARC y cartografía en España. Revista Catalana de Geografía, vol. xvii (46), 1-9. [Consulta: 20/10/2012]. Disponible en: <http://www.rcg.cat/articles.php?id=259>

Schaffner, J. (2009). The metadata is the interface better description for better discovery of archives and special collections, synthesized from user studies. Dublin: OCLC Research, $18 \mathrm{p}$. [Consulta: 30/10/2012]. Disponible en: <http:// www.oclc.org/resources/research/publications/ library/2009/2009-06.pdf>

Science Photo Library. (2012). Royal Astronomical Society. [Consulta: 20/10/2012]. Disponible en: $<$ http://www.sciencephoto.com/search?subtype =k eywords\&searchstring=royal+astronomical+society $\&$ Search. $x=21 \&$ Search. $y=12 \&$ media type=images \&license $=$ both\&channel $=$ all $>$

Shobbrook. R.; Genova, F. (1995). SIMBAD for Librarians. Vistas in Astronomy, vol. 39, 155-160.

SIMBAD (2012a). Página web principal. [Consulta: 18/08/2012]. Disponible en: <http://simbad.ustrasbg.fr/simbad/>

SIMBAD (2012b). Object classification in SIMBAD. [Consulta: 22/10/2012]. Disponible en: $<$ http://simbad.u-strasbg.fr/simbad/simdisplay?data=otypes $>$

SIMBAD (2012c). Help page. [Consulta: 22/10/2012]. Disponible en: <http://simbad.u-strasbg.fr/simbad/ sim-help?Page $=$ sim-fscript $>$

SIMBAD (2012d). Description of the queriable fields. [Consulta: 18/08/2012]. Disponible en: <http:// simbad.u-strasbg.fr/simbad/sim-fsam>

Verbunt, F.; Van Gent, R. H. (2010a). The star catalogue of Hevelius. Machine-readable version and comparison with the modern Hipparcos Catalogue. Astronomy \& Astrophysics, vol. 516, A29, JuneJuly, 1-22. [Consulta: 13/09/2013]. Disponible en: <http://www.aanda.org/articles/aa/pdf/2010/08/ aa14003-10.pdf>

Verbunt, F.; Van Gent, R. H. (2010b). Three editions of the star catalogue of Tycho Brahe. Machine-readable versions and comparison with the modern Hipparcos Catalogue. Astronomy \& Astrophysics, vol. 516, A28, June-July, 1-24. [Consulta: 13/09/2013]. Disponible en: <http://www.aanda.org/articles/aa/ pdf/2010/08/aa14002-10.pdf >

Verbunt, F.; Van Gent, R. H. (2012). The star catalogues of Ptolemaios and Ulugh Beg. Machine-readable version and comparison with the modern HIPPARCOS Catalogue. Astronomy \& Astrophysics, vol. 544, August, A31, 1-34. [[Consulta: 13/09/2013]. Disponible en: <http://www.aanda.org/articles/aa/ pdf/2012/08/aa19596-12.pdf>

Wenger, M. (2007). The New Version of SIMBAD. En: Ricketts, S.; Birdie, C.; Isaksson, E. (eds.). Library and Information Services in Astronomy V, vol. 377, p. 197-198.

Wenger, M.; Oberto, A. (2010). Data Mining in the SIMBAD Database Web Log Files. En: Mizumoto, Y.; Morita, K. I.; Ohishi, M. (eds). Astronomical Data Analysis Software and Systems XIX. ASP Conference Series, vol. 434, 453-456. [Consulta: 22/05/2011]. Disponible en: <http://articles.adsabs.harvard.edu/ cgi-bin/nph-iarticle_query?2010ASPC..434..453W\& defaultprint $=$ YES\&filetype $=$. .pdf $>$ 
Wenger, M. y otros (2000). The SIMBAD astronomical database. The CDS Reference Database for Astronomical Objects. Astronomy and

Astrophysics, 1-14. [Consulta: 22/05/2011].

Disponible en: <http://arxiv.org/PS_cache/astro-

ph/pdf/0002/0002110v1.pdf>
Wikipedia (2012). Magnitud aparente. [Consulta: 30/10/2012]. Disponible en: <http://es.wikipedia. org/wiki/Magnitud_aparente> 